\title{
Upper gastrointestinal bleeding in caracas hemorragia digestiva superior en caracas
}

\begin{abstract}
Materials and methods: The aim of this research is to describe endoscopic findings in patients with acute Upper Gastrointestinal bleeding. The sample consisted of 131 patients with signs or symptoms of Upper Gastrointestinal Bleeding during the first half of 2012 . Non-experimental, descriptive and prospective research. Mean, mode and median for numerical variables and percentages were used.

Results and discussion: During the first half of 2012 were performed 2602 endoscopies, a total of 136 endoscopies were maid whose indication was upper digestive bleeding. Endoscopy was performed on 131 patients, $52.2 \%$ were female, $36.8 \%$ of endoscopies were performed in people of 60 year or older. $48.9 \%$ of patients had no comorbidity. $80.1 \%$ of patients received no medication. The most frequent endoscopic finding was Peptic Ulcer Disease (44.1\%). In $70.6 \%$ of cases no endoscopic therapy was applied.

Conclusions: Study findings are similar to those described in the national and international literature, differences were observed by increased frequency of neoplasms, increased use of argon plasma coagulation and low recurrence of bleeding. This research extended several recommendations.
\end{abstract}

Keywords: upper gastrointestinal bleeding, hematemesis, melena, endoscopic findings, endoscopic treatment
Volume 3 Issue 2 - 2015

Daniel Tepedino Peluso, Chuymar De Jesús Betancourt Torrealba, Hilda María Pérez Useche

Department of Gastroenterology, Hospital Universitario de Caracas, Venezuela

Correspondence: Daniel Tepedino Peluso, C.I.VI5.646.405.Av. Humboldt cruce con Calle Baldo Urb. Bello Monte, Residencia Crystal Plaza, piso 4, Apto 4-B, Parroquia El Recreo, Municipio Libertador, Código postal 1050, Caracas-Venezuela,Tel 5.84|2707|462, Email d.tepedino@gmail.com

Received: October 23, 2015 | Published: December 04, 2015

\section{Introduction}

With more than $10 \%$ mortality Gastrointestinal Bleeding is a relevant entity, those patients who survive an episode have $15 \%$ chance of having a second episode despite adequate medical and endoscopic treatment.About peptic Ulcer Disease, currently most common cause of upper gastrointestinal bleeding, it was established that has a great economic impact; in the US it is estimated that the cost of absenteeism and medical and endoscopic therapy associated could reach 5.65billion per year. ${ }^{1}$ A Dutch study estimated that the cost of the complications of peptic Ulcer disease: bleeding, perforation or the combination of both was for 2004 of $€ 12,000, € 19,000$ and $€ 26,000$ respectively. $^{2}$

Recent research reports that endoscopic injection of adrenaline alone is a inferior treatment, a second treatment modality should be used in most cases. The combination treatment approach has been shown to significantly reduce recurrent bleeding, need for surgery, use of blood products, length of hospital stay and mortality. ${ }^{3}$

The frequency of Gastrointestinal Bleeding, morbidity, mortality and costs associated with it in Latin American countries are less documented.This research aims to provide information that will improve the knowledge about Upper Gastrointestinal Bleeding in Caracas, Venezuela and Latin America, will collaborate with the optimization of human and material resources in gastroenterology services, emergency services and Digestive Endoscopy Units.

\section{Methods}

It was a non-experimental, descriptive and prospective research. The study aimed to describe the findings and therapeutic on Upper Gastrointestinal Endoscopy in patients with Upper Gastrointestinal Bleeding at the Gastroenterology Department of the Hospital Universitariode Caracas in 2012. The population consisted of patients evaluated by the doctors of the Gastroenterology Department of the Hospital Universitariode Caracas at the Emergency Room, hospitalization or consults during the first half of 2012 and that merited emergency endoscopic evaluation. The sample consisted of 131 patients over 12years showed unmistakable signs or symptoms of Acute Upper Gastrointestinal Bleeding and who underwent upper gastrointestinal endoscopy at the Department of Gastroenterology at that hospital. Variables like Age, Sex, First endoscopy or successively, comorbidities, use of anti-inflammatory drugs, use of Esteroids drugs, Endoscopic Findings and Endoscopic Therapeutic (if performed) were considered.

The Gastroscopies practiced were performed by doctors Gastroenterologists (sometimes the Researchers) or residents in training, under the supervision of Gastroenterologists belonging to the Department of Gastroenterology of the Hospital Universitariode Caracas. Measures of central tendency (mean, mode and median) for numeric variables and frequency (percentages for nominal) were used to report the frequency of endoscopic findings in patients with Upper Gastrointestinal Bleeding. Finally, the similarities and differences observed with other populations evaluated in other national and international hospitals were established.A statistical consultant oversaw the calculations in SPSS and other related procedures.

\section{Results and Discussion}

During the first half of 2012, 2602 digestive endoscopies were performed at the Gastroenterology Department of the Hospital Universitariode Caracas, 1565 were Gastroscopies and 1037 were Colonoscopies. A total of 136 endoscopies were performed in patients with Upper Gastrointestinal Bleeding. Gastroscopies were performed on 131 patients, $52.2 \%$ were female, ages ranged from 17 87 years (mean 53.6; mode 52, median 54, standard deviation \pm 18.13 years). $36.8 \%$ of Gastroscopies were performed in people 60 and older (Figure 1). 


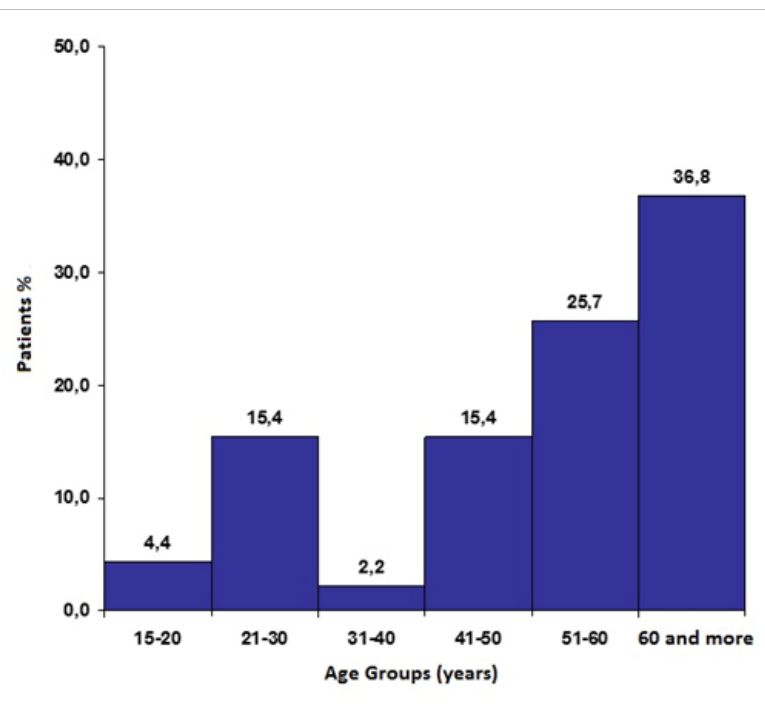

Figure I Endoscopic findings in patients with Upper Gastrointestinal Bleeding. Sample distribution by age.

No medical conditions were observed at $48.9 \%$ of patients, in the remaining 67 patients one or more conditions were observed within these the most frequent was High Blood Pressure (17.6\%) followed by Ischemic Heart Disease and Liver Cirrhosis. Were observed several medical conditions: chronic, metabolic, vascular, renal, neoplasms and other diseases, and one pregnant. The $80.1 \%$ of patients received no medication, $18.4 \%$ were treated with NSAIDs and steroid $1.5 \%$. The number of endoscopic findings varied from one $(52.9 \%)$ to none $(8.8 \%)$. The most frequent endoscopic finding was peptic Ulcer disease in $44.1 \%$ of cases (Table 1) placed more frequently at the Stomach $(25 \%)$. The most common location of gastric ulcer was Antrum (74\%) in the duodenal bulb in (51\%). Forrest III Ulcers were observed in most cases (76.6\% ofgastric and $59.8 \%$ of duodenal), followed by Forrest IIC (Table 2). Erosive Gastropathy (23.5\%), Esophagitis (14.7\%) Esophageal varices (13.2\%) and Gastrointestinal Neoplasms (13.2\%) were frequent findings.

Table I Endoscopic findings in patients with Upper Gastrointestinal Bleeding. Distribution of the sample according to endoscopic findings

\begin{tabular}{lll}
\hline Hallazgos endoscópicos & $\mathbf{n}$ & $\%$ \\
\hline Gastric Ulcer & 34 & 25.0 \\
Gastric Erosions & 32 & 23.5 \\
Duodenal Ulcer & 26 & 19.1 \\
Esophagitis & 20 & 14.7 \\
Esophageal Varices & 18 & 13.2 \\
Portal Hypertensive Gastropathy & 16 & 11.8 \\
Duodenal Erosions & 15 & 11.0 \\
Gastric Cancer & 15 & 11.0 \\
Hemorrhagic Gastropathy & 10 & 7.4 \\
Mallory-Weisslesion & 5 & 3.7 \\
Angiodysplasia & 5 & 3.7 \\
Congestive Gastropathy & 4 & 2.9 \\
Duodenal Tumor & 3 & 2.2 \\
Gastroesophageal Varices tipo I & 2 & 1.5 \\
Esophageal Foreign Body & 1 & 0.7 \\
Normal & 12 & 8.8
\end{tabular}

Table 2 Endoscopic findings in patients with upper gastrointestinal bleeding Distribution of the sample according to location of the ulcer

\begin{tabular}{lll}
\hline Ulcer & $\mathbf{n}$ & $\%$ \\
\hline Gastric & & \\
Forrest III & 36.0 & 42.9 \\
Forrest IIC & 5.0 & 6.0 \\
Forrest IB & 4.0 & 4.8 \\
Forrest IIA & 2.0 & 2.4 \\
Duodenal & & \\
Forrest III & 22.0 & 26.2 \\
Forrest IIC & 7.0 & 8.3 \\
Forrest IIB & 5.0 & 6.0 \\
Forrest IB & 2.0 & 2.4 \\
Forrest IA & 1.0 & 1.2 \\
Total & $\mathbf{8 4}$ & $\mathbf{1 0 0 . 0}$ \\
\hline
\end{tabular}

$70.4 \%$ of cases no endoscopic therapy was applied for not being indicated, $17.8 \%$ one method was applied and the remaining $11.8 \%$ a combination of two methods were used. The most commonly used monotherapy was the ligation of Esophageal Varices with elastic band (9.6\%), it was applied to 13 patients who had Large Esophageal Varices (BAVENO) with active bleeding or stigmata of recent bleeding. The second monotherapy was Argon Plasma Coagulation (8.1\%). The combined therapy more used was sclerosis with Adrenaline and later sclerosis with Alcohol (8.9\%). Two cases required surgical treatment because of endoscopic therapy failure $(1.5 \%$, a patient with advanced gastric cancer and one with a pancreatic tumor with extension into the duodenum) (Table $3 \& 4$ ).

Table 3 Endoscopic findings in patients with upper gastrointestinal bleeding. Distribution of the sample according to endoscopic therapy

\begin{tabular}{|c|c|c|}
\hline Endoscopic therapy & $\mathbf{N}$ & $\%$ \\
\hline None & 95 & 70.4 \\
\hline Elastic Band Ligation & 13 & 9.6 \\
\hline $\begin{array}{l}\text { Combined:Adrenaline and Alcohol } \\
\text { Injection }\end{array}$ & 12 & 8.9 \\
\hline Argon Plasma Coagulation & II & 8.1 \\
\hline $\begin{array}{l}\text { Emergency Surgery due to } \\
\text { Endoscopic Therapy Failure }\end{array}$ & 2 & $\mathrm{I} .5$ \\
\hline $\begin{array}{l}\text { Combined:Adrenaline injection and } \\
\text { Argon Plasma Coagulation }\end{array}$ & 2 & 1.5 \\
\hline Total & $135 *$ & 100 \\
\hline
\end{tabular}

*A Esophageal Foreign Body was removed from one Patient but it was not considered therapy for Upper Gastrointestinal Bleeding.

Five patients required a second endoscopic examination because of recurrent or persistent bleeding (3.7\% of cases): a man of 56years old with Gastric Cancer who required emergency surgery, a male of 68 years old with Pancreatic cancer duodenal extension required emergency surgery, a male of 42 years with Liver Cirrhosis with a second Esophageal variceal Bleeding that was treated with another elastic band, a 31year old female with Stomach Ulcers without new endoscopic findings, a male of 48years old with Diabetes Mellitus type 2 had Gastric Angiodysplasia previously treated with Argon plasma without new findings (Colonoscopy revealed Angiodysplasia at Cecum and was treated with Argon Plasma coagulation). During the first half of 2012 Upper Gastrointestinal Bleeding was the indication $5.2 \%$ of all endoscopies and $8.7 \%$ of the Gastroscopies, being relevant. ${ }^{4}$ 
Table 4 Endoscopic findings in patients with Upper Gastrointestinal Bleeding. Sample distribution by finding and therapeutics

\begin{tabular}{|c|c|c|c|c|c|c|}
\hline Endoscopic finding & $\begin{array}{l}\text { Elastic band } \\
\text { ligation }\end{array}$ & $\begin{array}{l}\text { Adrenaline } \\
\text { and alcohol } \\
\text { injection }\end{array}$ & $\begin{array}{l}\text { Argon plasma } \\
\text { coagulation }\end{array}$ & $\begin{array}{l}\text { Adrenaline injection } \\
\text { plus argon plasma } \\
\text { coagulation }\end{array}$ & $\begin{array}{l}\text { Emergency } \\
\text { surgery }\end{array}$ & Total \\
\hline Large Esophageal Varices (BAVENO) & 13 & & & & & 13 \\
\hline Advanced Gastric Cancer (Borrmann III) & & & 5 & & 1 & 6 \\
\hline Duodenal Ulcer (Forrest IIB) & & 5 & & & & 5 \\
\hline Gastric Angiodysplasia & & & 5 & & & 5 \\
\hline Gastric Ulcer (Forrest IB) & & 4 & & & & 4 \\
\hline Gastric Ulcer (Forrest IIA) & & 1 & & I & & 2 \\
\hline Duodenal Ulcer (Forrest IB) & & 2 & & & & 2 \\
\hline Duodenal Ulcer (Forrest IA) & & & & 1 & & 1 \\
\hline Pancreatic Tumor with duodenal extension & & & & & 1 & 1 \\
\hline Advanced Gastric Cancer (Borrmann IV) & & & 1 & & & 1 \\
\hline Total & 13 & 12 & II & 2 & 2 & 40 \\
\hline
\end{tabular}

In terms of demographic characteristics, associated medical conditions and current or recent medication it was no difference with those described in the literature. ${ }^{5-9,10-12}$. Endoscopic findings were discordant with those published in America and Europe by Gastric Neoplasms (13.3\%), Gastric Neoplasm were found to be more frequent than reported. This research describe one case of Esophageal Foreign Body as a cause of Upper Gastrointestinal Bleeding, a very rare cause. ${ }^{4,13}$ Analyzing endoscopic therapy used is noteworthy that in $70.6 \%$ of cases it was not required, suggesting the possibility that pre-endoscopic medical treatment administered was beneficial for patients with gastric ulcers and erosions, improving their prognosis, also it was associated with less severe cases of bleeding. ${ }^{4,6,14}$

Endoscopic Elastic Band Ligation and Argon Plasma Coagulation methods were widely used compared to that described in American literature, probably this was related to: 1) The high number of patients with Variceal Bleeding observed, 2) the fact that this is a Hospital with Hepatology Consult and postgraduate training and 4) because of the lack of such therapeutic methods in other Hospitals of the public health system. ${ }^{4,15-16}$

At the Gastroenterology department of the Hospital Universitariode Caracas combined methods for the control of Gastrointestinal Bleeding due to Gastric Ulcers were employed, it was observed the use of Adrenaline and Alcohol, and in conjunction with Argon Plasma Coagulation according to current recommendations of the American literature. Endoscopic injection of Adrenaline as monotherapy was no used. ${ }^{3,5,17}$

During the removing of aEsophageal Foreign Body (porkbone) which left a bleeding laceration that required Adrenaline and Hypertonic solution injection was documented, this is a rarecause of hematemesis and Upper Gastrointestinal Bleeding., ${ }^{4,13-18}$ The use of other endoscopic therapeutic methods such as Clips or Heater Probe was limited because of their availability. In accordance with current guidelines from the American Society for Gastrointestinal Endoscopy (ASGE), The Gastroenterology Department of the Hospital Universitariode Caracas showed lower mortality and recurrence of bleeding than described in American literature. $4,5,14,20,21$

\section{Conclusion}

This research contributes with information on the demographic and endoscopic characteristics of 131 patients who had Upper Gastrointestinal Bleeding during the first half of 2012 at the Hospital Universitariode Caracas. The most frequently involved was the female sex $(52.2 \%)$, more than one third of patients were over 60years. $48.9 \%$ of patients showed no associated medical condition, the most common associated medical condition was High Blood Pressure (17.6\%). $80.1 \%$ of patients received no medication, $18.4 \%$ used non steroid anti-inflammatory drugs and $1.5 \%$ steroids drugs.

The number of endoscopic findings varied from one (52.9\%) to none $(8.8 \%)$. The most frequent endoscopic finding was Peptic Ulcer disease in $44.1 \%$ of cases (Table 2) located more frequently at Stomach (25\%). Erosive Gastropathy (23.5\%), Esophagitis (14.7\%) Esophageal Varices (13.2\%) and Neoplasms Gastrointestinal $(13.2 \%)$ were frequent findings. $70.4 \%$ of cases no endoscopic therapy was applied, $17.8 \%$ of cases one method was applied and the remaining $11.8 \%$ of cases a combination of two methods was used. The most commonly used monotherapy was the Elastic Band Ligation of Esophageal Varices (9.6\%) followed by the use of Argon Plasma Coagulation $(8.1 \%)$. The more used combined therapy was Adrenaline and Alcohol injection (8.1\%). Two cases required surgical treatment because of Endoscopic Therapy Failure (Advanced Gastric Cancer and Pancreatic Tumor with duodenal extension). Five patients required a subsequent endoscopy because relapse or recurrence of bleeding (3.7\% of cases).

\section{Recommendations}

Whereas the findings reveal that Peptic Ulcer disease is the most frequently cause of Upper Gastrointestinal Bleeding, themedical and paramedical training should focus on optimal management of this disease. Considering the large number of patients with variceal bleeding and the widespread use of Argon Plasma Coagulation, measures must be taken to ensure the availability of supplies and proper functioning of equipments.

The Hospital Universitariode Caracas lacks of intermediate care areas at both Emergency Room and Hospitalization, their creation will provide an opportunity to ensure optimal care to patients at high risk of death. Has been universally described the use of Risk Scores in patients with Gastrointestinal Bleeding, also the standardization of care with Gastrointestinal Bleeding protocols, their use could maximize resources and reduce associated morbidity and mortality.

Endoscopy records must be digitalized for ease of use, study and analysis. This records are an infinite source of valuable information that actually is very inaccessible and unfriendly to the user. Research should be promoted and encourage. Research and publishing must be a habit. The descriptions made in this research provide evidence of 
strong similarities between the evaluated sample and the Venezuelan and international population. These data should be complemented investigating causes of Lower Gastrointestinal Bleeding and Occult Gastrointestinal Bleeding and with the use of analytical statistics.

\section{Acknowledgements}

The authors want to thank all the staff of Gastroenterology Department of the Hospital Universitario de Caracas.

\section{Conflicts of interest}

Author declares there are no conflicts of interest.

\section{Funding}

None.

\section{References}

1. Sonnenberg A, Everhart JE. Health impact of peptic ulcer in the United States. Am J Gastroenterol. 1997;92(4):614-620.

2. Leest $\mathrm{H}$, van Dieten $\mathrm{H}$, van Tulder M, et al. Costs of treating bleeding and perforated peptic ulcers in the Netherlands. $J$ Rheumatol. 2004;3194:788-791.

3. Vergara M, Calvex X, Gisbert JP. Epinephrine injection versus epinephrine injection and a second endoscopic method in high risk bleeding ulcers. Cochrane Database Syst Rev. 2007;18(2):CD 005584.

4. Barkun AN, Bardou M, Kuipers EJ, et al. International consensus recommendations on the management of patients with nonvariceal upper gastrointestinal bleeding. Ann Intern Med. 2010;152(2):101-113.

5. Albeldawi M, Qadeer MA, Vargo JJ. Managing acute upper GI bleeding, preventing recurrences. Cleve Clin J Med. 2010;77(2):131-142.

6. Lewis JD, Bilker WB, Brensinger C, et al. Hospitalization and mortality rates from peptic ulcer disease and GI bleeding in the 1990s: relationship to sales of nonsteroidal anti-inflammatory drugs and acid suppression medications. Am J Gastroenterol. 2002;97(10):2540-2549.

7. Viviane A, Alan BN. Estimates of costs of hospital stay for variceal and non variceal upper gastrointestinal bleeding in the United States. Value Health. 2008;11(1):1-3.

8. Pilkington KB, Wagstaff MJ, Greenwood JE. Prevention of gastrointestinal bleeding due to stress ulceration: a review of current literature. Anaesth Intensive Care. 2012;40(2):253-259.
9. Yavorski RT, Wong RK, Maydonovitch C, et al. Analysis of 3,294 cases of upper gastrointestinal bleeding in military medical facilities. $\mathrm{Am} \mathrm{J}$ Gastroenterol. 1995;90(4):568-573.

10. Añez, M, González H, Pacheco JL, et al. El valor de la endoscopia de emergencia en hemorragia digestiva superior. GEN. 1990;44(2):125133.

11. Morillo ME. Estudio comparativo entre Omeprazole Oral y Esclerosis Endoscópica en Úlcera péptica con vaso visible no sangrante (Thesis). Venezuela, Caracas: Universidad Central de Venezuela; 1997.

12. Souk H, Hitti K. Eficacia de la Escala de Baylor para predecir Resangramiento en la Hemorragia Digestiva Superior por Úlcera Gástrica o Duodenal (Thesis). Venezuela, Caracas: Universidad Central de Venezuela; 1998.

13. Vasquez JL. Endoscopia digestiva: diagnostica y terapeutica. 1st edn Spain: Madrid; 2009. pp.749-768.

14. Mavares J, Ramírez F, Cifuentes C, et al. Factores clínicos pronósticos de mortalidad en hemorragia digestiva superior. GEN. 47(4):199-203.

15. Salazar P. Ligadura de Várices Esofágicas. Alcance del procedimiento (Thesis). Caracas Universidad Central de Venezuela, Venezuela. 2000.

16. Salazar P, González JC, Louis C. Ligaduras de Várices Esofágicas: Alcance del procedimiento. AVFT. 2002;21(2):190-194.

17. Chung SS, Lau JY, Sung JJ, et al. Randomised comparison between adrenaline injection alone and adrenaline injection plus heater probe treatment for actively bleeding peptic ulcers. $B M J$. 1997;314(7090):1307-1311

18. Savides T, Jensen D Gastrointestinal Bleeding. In: Feldman M, Friedman L, Brandt L, Editors. Gastrointestinal and Liver Disease. 9th edn. Canada: Elsevier; pp. 285-322.

19. Choichi Sugawa, Hiromi Ono, Mona Taleb, et al.Endoscopic management of foreign bodies in the upper gastrointestinal tract: A review. World J Gastrointest Endosc. 2014;6(10):475-481.

20. Jansen L, Leffers P, Hermans M, et al. Identification of patients with upper gastrointestinal bleeding who do not need immediate treatment. Neth J Med. 2011;69(9):384388.

21. American Society for Gastrointestinal Endoscopy. The role of endoscopy in the management of patients with peptic ulcer disease. 2010;71(4). 